\title{
Antimicrobial Susceptibility and Clonal Relation Between Acinetobacter baumannii Strains at a Tertiary Care Center in Turkey
}

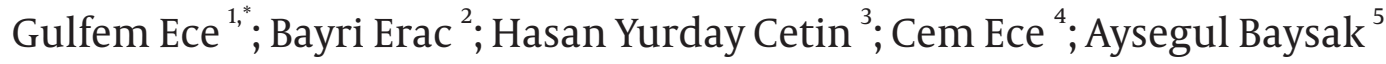 \\ ${ }^{1}$ Department of Medical Microbiology, School of Medicine, Izmir University, Izmir, Turkey \\ ${ }^{2}$ Department of Pharmaceutical Microbiology, School of Pharmacy, Ege University, Izmir, Turkey \\ ${ }_{3}^{3}$ Department of Anesthesiology and Reanimation, School of Medicine, Izmir University, Izmir, Turkey \\ ${ }^{4}$ Department of Anesthesiology and Reanimation, School of Medicine, Izmir University, Izm \\ 5 Department of Anesthesiology and Reanimation, Menemen State Hospital, Izmir, Trit
${ }_{\text {Department }}$ of Chest Diseases, School of Medicine, Izmir University, Izmir, Turkey \\ ${ }^{*}$ Corresponding author: Gulfem Ece, Department of Medical Microbiology, Medicalpark Hospital, School of Medicine, Izmir University, Yeni Girne Boulevard, 1825th St., No 12, \\ Karsıyaka, Izmir, Turkey. Tel:+90-2323995050, E-mail: gulfem.ece@izmir.edu.tr, gulfem.ece@gmail.com \\ Received: November 1, 2013; Revised: February 16, 2014; Accepted: March 9, 2014
}

\begin{abstract}
Background: Acinetobacter baumannii is an opportunistic pathogen, related with nosocomial infections such as bacteremia, urinary tract infections, and ventilator-associated pneumonia. Multidrug resistant (MDR) A. baumannii strains are first line causes of infection, especially in patients hospitalized at intensive care units (ICUs). Infection with MDR A. baumannii strains has a longer duration at ICUs and hospitals. There are studies using molecular methods which can differentiate MDR A. baumannii strains at the clonal level. This helps controlling these resistant strains and prevents their epidemy.

Objectives: The aim of our study was to investigate the antimicrobial susceptibility and clonal relationship between the A. baumannii strains isolated from our ICU.

Materials and Methods: The identification and antimicrobial susceptibility of $33 \mathrm{~A}$. baumannii strains were performed by automatized Vitek version 2.0. The clonal relationship among A. baumannii strains was analyzed using enterobacterial repetitive intergenic consensus (ERIC) polymerase chain reaction (PCR).

Results: Atotal of 33 A. baumannii strains were included in this study. A. baumannii complex strains were classified into seven clusters based on the fingerprint results. Our results revealed that two main clusters were responsible for the prevalence of A. baumannii complex strains at the ICU.

Conclusions: MDR A. baumannii strains cause an increment in morbidity and mortality, particularly in ICUs. The use of molecular epidemiological methods can help us with the detection of the pathogen and preventing from spreading of these resistant strains.
\end{abstract}

Keywords:Acinetobacter baumannii; Molecular Epidemiology; Enterobacterial Repetitive Intergenic Consensus Polymerase Chain Reaction

\section{Background}

Acinetobacter baumannii infections take place particularly in patients with serious underlying disorders, immunosuppressed ones, in patients undergoing invasive procedures, and the ones who have been treated with broad-spectrum antibiotics. Therefore, infections due to A. baumannii are commonly detected at intensive care units (ICUs) (1). Acinetobacter species are opportunistic pathogens which are prevalent in soil, waste water and hospital environment. Their colonization increases as the duration of hospitalization increases. Acinetobacter strains may colonize for approximately five months on hospital equipment $(2,3)$.

There was no resistance problem with Acinetobacter species in 1970s due to the limitation in broad-spectrum antibiotics usage and these isolates were not as important as today. However, recently, the wide and irrational use of broad-spectrum antibiotic has caused the emer- gence of multidrug resistant (MDR) pathogens in hospital settings $(4,5)$. Treatment of infections due to Acinetobacter species is a challenge due to relapses. More than 40 resistance genes are reported which can show genetic variance. Therefore, the strain can gain resistance to various antibiotics (6). MDR A. baumannii strains are the first line causes of infection, particularly in ICUs (7). Recently, there have been reports on MDR Acinetobacter species including aminoglycosides, quinolones, and carbapenems $(2,3,8)$.

There is rapid improvement in molecular diagnostic methods for detection of infectious pathogens. This has led to detailed researches on identification, clonal relationship, antibiotic resistance, and epidemiology of hospital infections. This also helps preventing the spread of resistant strains (9). There are studies using molecular methods which were able to differentiate

Copyright (C) 2015, Ahvaz Jundishapur University of Medical Sciences. This is an open-access article distributed under the terms of the Creative Commons Attribution-NonCommercial 4.0 International License (http://creativecommons.org/licenses/by-nc/4.0/) which permits copy and redistribute the material just in noncommercial usages, provided the original work is properly cited. 
Ece G et al.

MDR A. baumannii strains at the clonal level. This helps controlling these resistant strains and prevents their epidemy (10-12). There are various methods in detecting the epidemiology of hospital-acquired A. baumannii isolates.

\section{Objectives}

The aim of our study was to investigate the antimicrobial susceptibility and clonal relationship of A. baumannii strains isolated from wound, blood and tracheal secretion specimens by enterobacterial repetitive intergenic consensus polymerase chain reaction (ERIC PCR) at the ICU of a university hospital in Turkey.

\section{Materials and Methods}

\subsection{Bacterial Isolates, Identification and Antibacte- rial Susceptibility}

Thirty three A. baumannii strains isolated from wound, blood, and tracheal secretion specimens between January 1st 2013 and June 30th 2013 at the Izmir University School of Medicine Hospital ICU were included. The clinical specimens were cultivated on blood agar, chocolate agar, and eosin methylene blue (EMB) agar (Salubris, Turkey). The plates were incubated at $37^{\circ} \mathrm{C}$ for $48-72$ hours. One isolate per patient was used in the study. The identification and antimicrobial susceptibility of the strains were studied by automatized Vitek version 2.0 (Biomerieux, France). The Escherichia coli ATCC 25922, Pseudomonas aeruginosa ATCC 27853 and Klebsiella pneumoniae 700603 were used as quality control strains.

\subsection{Enterobacterial Repetitive Intergenic Consen- sus Polymerase Chain Reaction}

The clonal relationship among the $A$. baumannii strains was analyzed using ERIC-PCR (5'-AAG TAA GTG ACT GGG GTG AGC G-3') (Fermentas, Lithuania) (13). To evaluate similarity between the isolates, Jaccard coefficients were derived from the banding patterns (14). Dendrograms were constructed according to the unweighted pair group method with arithmetic mean method, using Jac- card coefficients and MEGA software version 4.0 (15). The components of the $50 \mu \mathrm{L}$ master mix are shown in Table 1. The amplification was as follows: one cycle $\left(94^{\circ} \mathrm{C}\right.$ for one minute), 30 cycles $\left(94^{\circ} \mathrm{C}\right.$ for one minute, $45^{\circ} \mathrm{C}$ for one minute, $72^{\circ} \mathrm{C}$ for two minutes), and $72^{\circ} \mathrm{C}$ for five minutes. The amplified products were imaged using a $0.5 \mu \mathrm{g} / \mathrm{mL}$ ethidium bromide-containing gel, prepared in $1 \%$ agarose in $1 \mathrm{x}$ Tris-borate-EDTA (TBE) buffer (Sigma, USA) under 120 $\mathrm{v}$ for 45 minutes and under the UV light. Gene RulerTM 50 bp DNA Ladder (Biolabs, New England) was used in detecting the size of the bands.

\section{Results}

A total of 33 A. baumannii strains were included in this study. The samples consisted of tracheal secrete (23), wound (2) and blood cultures (8). The antimicrobial susceptibility of A. baumannii isolates are shown in Table 2 . The ERIC-PCR gel image of the isolates is shown in Figure 1. A. baumannii complex strains were classified into seven clusters based on the fingerprinting results. The larger clusters consisted of 16 and 12 members and other clusters included only one member each (Figure 2). Our results revealed that two main clusters were responsible for the prevalence of A. baumannii complex strains at the ICU.

Table 1. Enterobacterial Repetitive Intergenic Consensus Polymerase Chain Reaction Master Mix ${ }^{a}$

\begin{tabular}{lc}
\hline Components of the Master Mix & Data \\
\hline $\mathbf{1 0 x}$ Enzyme Buffer, & $5 \mu \mathrm{L}(1 \mathrm{x})$ \\
$\mathbf{M g C l}_{\mathbf{2}}$ & $5 \mu \mathrm{L}(2.5 \mathrm{mM})$ \\
\hline DNTPs & $5 \mu \mathrm{L}(200 \mu \mathrm{M})$ \\
\hline ERIC-2 & $1 \mu \mathrm{L}(25 \mathrm{pmol})$ \\
\hline $\begin{array}{l}\text { Taq DNA polymerase (Fermen- } \\
\text { tas, Lithuania), }\end{array}$ & $0.5 \mu \mathrm{L}(2.5 \mathrm{U})$ \\
Sterile deionized water & $28.5 \mu \mathrm{L}$ \\
DNA & $5 \mu \mathrm{L}$ \\
\hline
\end{tabular}

${ }^{\mathrm{a}}$ Abbreviations: ERIC, enterobacterial repetitive intergenic consensus.

\begin{tabular}{|c|c|c|c|c|c|c|c|c|c|c|}
\hline A. baumannii & CAZ & FEP & TZP & IMP & MEM & AK & GN & TG & CT & SCF \\
\hline $\begin{array}{l}\text { Tracheal secretion } \\
(\mathbf{n}=23)\end{array}$ & 0 & 0 & 0 & $2(8.6)$ & $1(4.3)$ & $9(39.1)$ & $5(21.7)$ & $18(78.2)$ & $23(100)$ & 0 \\
\hline $\operatorname{Blood}(n=8)$ & $1(12.5)$ & $1(12.5)$ & $1(12.5)$ & $1(12.5)$ & $1(12.5)$ & $4(50)$ & $3(37.5)$ & $8(100)$ & $8(100)$ & $2(25)$ \\
\hline Wound $(n=2)$ & 0 & 0 & 0 & 0 & 0 & 0 & 0 & $1(50)$ & $2(100)$ & 0 \\
\hline
\end{tabular}

a Abbreviations: AK; amikacin, CAZ; ceftazidime, CT; colistin, FEP; cefepime, GN; gentamycin, IMP; imipenem, MEM; meropenem, SCF; sulbactam/ cefoperazone, TG; tigecycline, TZP; tazobactam/piperacillin.

b Data are presented as No. (\%). 


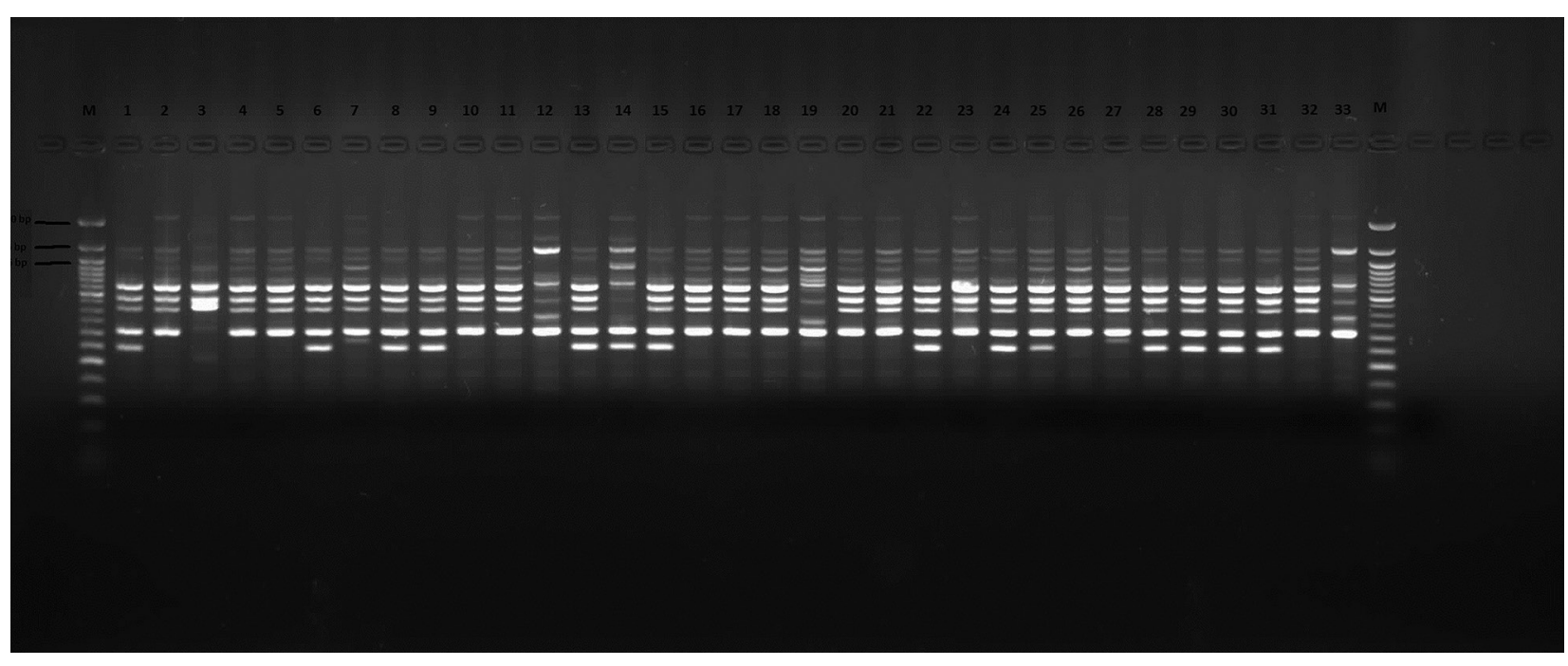

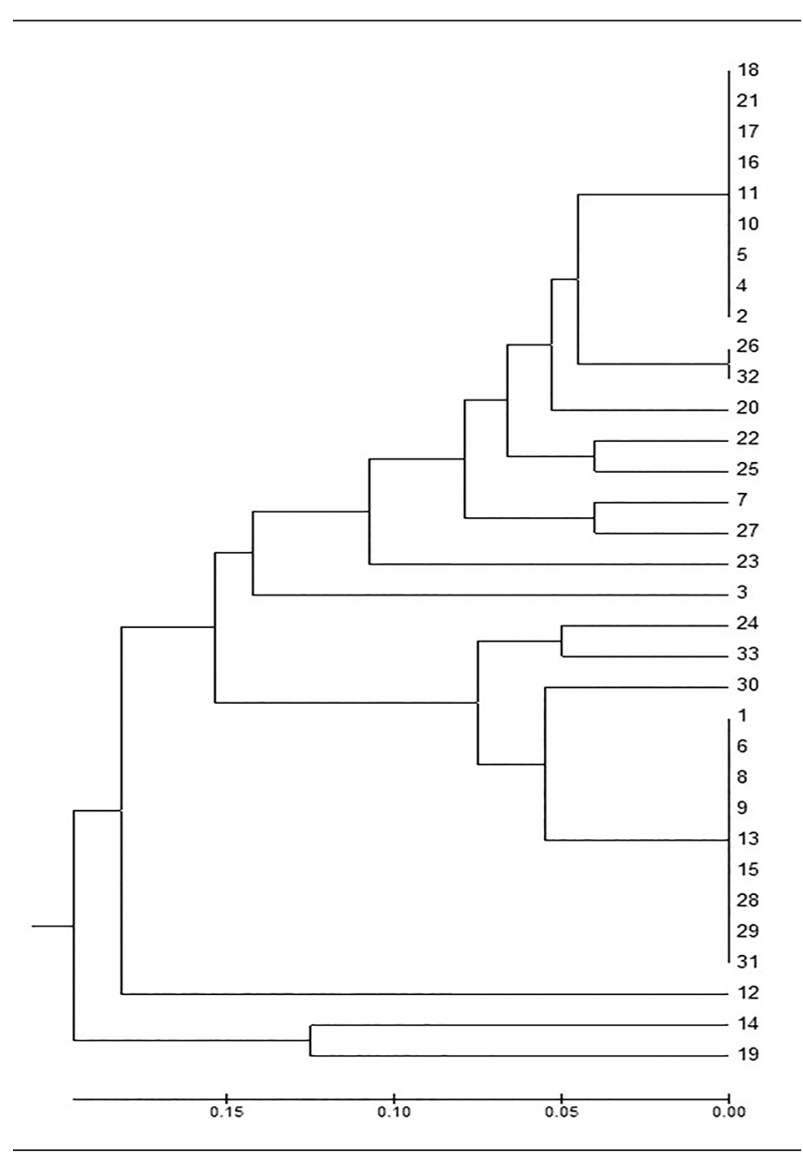

Figure 2. Dendrogram of the Isolates

\section{Discussion}

A. baumannii is a healthcare-associated pathogen, increasingly being reported as the cause of nosocomial in- fections, especially at ICUs (16-18). Infection with MDR A. baumannii strains has a longer duration at ICUs and hospitals. Besides, the mortality rates and treatment costs are higher among these patients $(19,20)$. Surveillance systems for nosocomial infections must be rapid, reliable, and capable of distinguishing between related and unrelated bacterial strains, particularly in $\operatorname{ICUs}(21,22)$.

There have been studies using molecular methods which have been able to differentiate MDR A. baumannii strains at the clonal level. This helps controlling these resistant strains and prevents their epidemy (10-12). Microbial typing methods have become an essential section of clinical microbiology laboratories. These methods consist of PCR multilocus enzyme electrophoresis (MLEE), multilocus sequence typing (MLST), pulsed-field gel electrophoresis (PFGE), restriction fragment length polymorphisms (RFLP), DNA sequencing, ribotyping, randomly amplified polymorphism DNA (RAPD), amplified fragment length polymorphism (AFLP) and repetitive sequence-based PCR (REP-PCR) (23). The REP-PCR method uses primers that target noncoding repetitive sequences interspersed throughout the bacterial DNA and is an established approach for subspecies classification (24). The method is easy to apply and has the advantage of working with many isolates at the same time. Besides, due to its high resolution, phylogenetic analysis can be carried out. There are also disadvantages in ERIC; primers being affected by PCR conditions and band profiles may not be distinguishable (25).

Mathai et al. (26) worked with random amplified polymorphic DNA (RAPD) method to detect the molecular epidemiology of 27 hospital-acquired A. baumannii strains isolated from respiratory tract specimens. The authors have detected various clones at the hospital. In our study, The ERIC-PCR gel image of A. baumannii complex strains 
indicated seven clusters based on the fingerprinting results. Yong et al. (27) reported 23 different patterns among PER-1-positive Acinetobacter strains by PFGE method. Most of the strains were isolated from ICU which may indicate clonal spread. Our study indicated seven clusters. In another study in Turkey; the clonal relationship between nosocomial A. baumannii strains was detected by RAPDPCR and PFGE; $80 \%$ of 41 A. baumannii strains belonged to genotype 3. Thirty two patients were hospitalized in ICU and thus, a clonal spread was considered (28). In our study, the largesr clusters consisted of 16 and 12 members and other clusters included only one member each.

Akalin et al. (29) detected 12 different genotypes in 120 A. baumannii isolates during a three-year period by RAPDPCR method. The strains consisted of surveillance isolates, clinical strains and ICU isolates. The authors considered this data as cross-contamination and environmental contamination due to A. baumannii.

Carbapenems are the first line therapy for MDR A. baumannii strains. Increase in carbapenemase production resistance has been detected due to its over usage. Ozdem et al. (30) reported carbapenem resistance $32 \%$ in 2007, which increased to 80\% in 2010 among A. baumannii strains. Irrational and prevalent use of antibiotics increases the resistance rate and causes trouble in treatment. In our study, carbapenem resistance was high similar to other studies. The resistance rate was $91.4 \%$ in tracheal secretion samples, $87.5 \%$ in blood cultures and 100\% in wound cultures. Colistin is an effective antibiotic for MDR A. baumannii isolates (31). Dizbay et al. (32) reported $100 \%$ susceptibility to colistin for A. baumannii isolates. In our study, we also detected $100 \%$ susceptibility to colistin for A. baumannii strains. Besides, tigecycline was the second most susceptible antimicrobial agent.

MDR A. baumannii strains cause trouble in treatment. Increased resistance has led to an increment in morbidity, mortality, and cost. Therefore, molecular studies on clonal relationship and data on antimicrobial resistance are important in preventing epidemy and initiating effective treatment, especially in MDR strains such as A. baumannii. ICUs are sections of hospitals where invasive procedures (such as urinary catheterization and mechanical ventilation) are frequently held and a wide spectrum of antibiotics are administered. This may be the reason of detection of Acinetobacter infections at these units. The use of molecular epidemiological methods can help us with detection of the pathogen circulation at our university hospital.

\section{Authors' Contributions}

Gulfem Ece: acquisition of data and writing the manuscript, Bayri Erac: acquisition and writing the data, Hasan Yurday Cetin and Aysegul Baysak: acquisition of data, Cem Ece: writing and editing the manuscript.

\section{References}

1. Jiang W, Liu H, Yang YC, Xiao DW, Yu H, Huang WF, et al. Repeti-
tive-Sequence-Based Genotyping and Clonal Relationship Analysis of Acinetobacter baumannii in Nosocomial Infections. Lab Med. 2012;43(3):86-90.

2. Koneman WE, Procop WG, Schreckenberger CP, Woods LG. The nonfermentative gram negative bacilli. Koneman's Color Atlas and Textbook of Diagnostic Microbiology. 6th edBaltimore, Philadelphia: Lippincott Williams\&Wilkins; 2006.

3. Enoch DA, Birkett CI, Ludlam HA. Non-fermentative Gram-negative bacteria. Int J Antimicrob Agents. 2007;29 Suppl 3:S33-41.

4. Fournier PE, Richet H. The epidemiology and control of Acinetobacter baumannii in health care facilities. Clin Infect Dis. 2006;42(5):692-9.

5. Playford EG, Craig JC, Iredell JR. Carbapenem-resistant Acinetobacter baumannii in intensive care unit patients: risk factors for acquisition, infection and their consequences. J Hosp Infect. 2007;65(3):204-11.

6. Slama TG. Gram-negative antibiotic resistance: there is a price to pay. Crit Care. 2008;12 Suppl 4:S4.

7. Asik G. [Current approaches to explain the virulence of Acinetobacter baumannii]. Mikrobiyol Bul. 2011;45(2):371-80.

8. Van Looveren M, Goossens H, Arpac Steering Group . Antimicro bial resistance of Acinetobacter spp. in Europe. Clin Microbiol Infect. 2004;10(8):684-704.

9. Coelho JM, Turton JF, Kaufmann ME, Glover J, Woodford N, Warner $\mathrm{M}$, et al. Occurrence of carbapenem-resistant Acinetobacter baumannii clones at multiple hospitals in London and Southeast England. J Clin Microbiol. 2006;44(10):3623-7.

10. Consales G, Gramigni E, Zamidei L, Bettocchi D, De Gaudio AR. A multidrug-resistant Acinetobacter baumannii outbreak in intensive care unit: antimicrobial and organizational strategies. $J$ Crit Care. 2011;26(5):453-9.

11. La Forgia C, Franke J, Hacek DM, Thomson RB, Jr., Robicsek A, Peterson LR. Management of a multidrug-resistant Acinetobacter baumannii outbreak in an intensive care unit using novel environmental disinfection: a 38-month report. Am J Infect Control. 2010;38(4):259-63.

12. Garlantezec R, Bourigault C, Boles JM, Prat G, Baron R, Tonnelier $\mathrm{JM}$, et al. Investigation and management of an imipenem-resistant oxa-23 Acinetobacter baumannii outbreak in an intensive care unit. Med Mal Infect. 2011;41(8):430-6.

13. Luzzaro F, Mantengoli E, Perilli M, Lombardi G, Orlandi V, Orsatti A, et al. Dynamics of a nosocomial outbreak of multidrug-resistant Pseudomonas aeruginosa producing the PER-1 extendedspectrum beta-lactamase. J Clin Microbiol. 2001;39(5):1865-70.

14. Soll DR. The ins and outs of DNA fingerprinting the infectious fungi. Clin Microbiol Rev. 2000;13(2):332-70.

15. Tamura K, Dudley J, Nei M, Kumar S. MEGA4: Molecular Evolutionary Genetics Analysis (MEGA) software version 4.0. Mol Biol Evol.2007;24(8):1596-9.

16. Urban C, Segal-Maurer S, Rahal JJ. Considerations in control and treatment of nosocomial infections due to multidrug-resistant Acinetobacter baumannii. Clin Infect Dis. 2003;36(10):1268-74.

17. Misbah S, Hassan H, Yusof MY, Hanifah YA, AbuBakar S. Genomic species identification of Acinetobacter of clinical isolates by $16 \mathrm{~S}$ rDNA sequencing. Singapore Med J. 2005;46(9):461-4.

18. Yan ZQ, Shen DX, Cao JR, Chen R, Wei X, Liu LP, et al. Susceptibil ity patterns and molecular epidemiology of multidrug-resistant Acinetobacter baumannii strains from three military hospitals in China. Int J Antimicrob Agents. 2010;35(3):269-73.

19. Sunenshine RH, Wright MO, Maragakis LL, Harris AD, Song X Hebden J, et al. Multidrug-resistant Acinetobacter infection mortality rate and length of hospitalization. Emerg Infect Dis. 2007;13(1):97-103.

20. Lee NY, Lee HC, Ko NY, Chang CM, Shih HI, Wu CJ, et al. Clinical and economic impact of multidrug resistance in nosocomial Acinetobacter baumannii bacteremia. Infect Control Hosp Epidemiol. 2007;28(6):713-9.

21. McGowan JE, Jr., Tenover FC. Confronting bacterial resistance in healthcare settings: a crucial role for microbiologists. Nat Rev Microbiol. 2004;2(3):251-8.

22. Pendle S, Jelfs P, Olma T, Su Y, Gilroy N, Gilbert GL. Difficulties in detection and identification of Enterococcus faecium with low- 


\section{Ece G et al.}

level inducible resistance to vancomycin, during a hospital outbreak. Clin Microbiol Infect. 2008;14(9):853-7.

23. Healy M, Huong J, Bittner T, Lising M, Frye S, Raza S, et al. Microbial DNA typing by automated repetitive-sequence-based PCR. J Clin Microbiol. 2005;43(1):199-207.

24. Fontana C, Favaro M, Minelli S, Bossa MC, Testore GP, Leonardis F, et al. Acinetobacter baumannii in intensive care unit: a novel system to study clonal relationship among the isolates. BMC Infect Dis. 2008;8:79.

25. Rademaker JLW, Savelkoul P. PCR amplification-based microbial typing. In: Persing DH, Tenover FC, Versalovic J, Tang YW, Unger E. R. , Relman DA, et al editors. Molecular Microbiology: Diagnostic Principles and Practice.. Washington DC: ASM Press; 2004. pp. 197-221.

26. Mathai E, Kaufmann ME, Richard VS, John G, Brahmadathan $\mathrm{KN}$. Typing of Acinetobacter baumannii isolated from hospitalacquired respiratory infections in a tertiary care centre in southern India. J Hosp Infect. 2001;47(2):159-62.

27. Yong D, Shin JH, Kim S, Lim Y, Yum JH, Lee K, et al. High prevalence of PER-1 extended-spectrum beta-lactamase-producing
Acinetobacter spp. in Korea. Antimicrob Agents Chemother 2003;47(5):1749-51.

28. Alp E, Esel D, Yildiz O, Voss A, Melchers W, Doganay M. Genotypic analysis of Acinetobacter bloodstream infection isolates in a Turkish university hospital. Scand I Infect Dis. 2006;38(5):335-40.

29. Akalin H, Ozakin C, Gedikoglu S. Epidemiology of Acinetobacter baumannii in a university hospital in Turkey. Infect Control Hosp Epidemiol. 2006;27(4):404-8.

30. Ozdem B, Gurelik FC, Celikbilek N, Balikci H, Acikgoz ZC. [Antibiotic resistance profiles of Acinetobacter species isolated from several clinical samples between 2007-2010]. Mikrobiyol Bul. 2011;45(3):526-34

31. Kallel H, Bahloul M, Hergafi L, Akrout M, Ketata W, Chelly H, et al. Colistin as a salvage therapy for nosocomial infections caused by multidrug-resistant bacteria in the ICU. Int J Antimicrob Agents. 2006;28(4):366-9.

32. Dizbay M, Altuncekic A, Sezer BE, Ozdemir K, Arman D. Colistin and tigecycline susceptibility among multidrug-resistant Acinetobacter baumannii isolated from ventilator-associated pneumonia. Int J Antimicrob Agents. 2008;32(1):29-32. 